\title{
A STUDY OF 100 CASES OF LATERAL INTERNAL SPHINCTEROTOMY FOR FISSURE-IN-ANO
}

\author{
Ravichandran Kailasam Subramaniam ${ }^{1}$, Jeena Josephine ${ }^{2}$
}

${ }_{1}^{1}$ Associate Professor, Department of General Surgery, MAPIMS.

${ }^{2}$ Assistant Professor, Department of General Surgery, MAPIMS.

\begin{tabular}{l}
\hline ABSTRACT \\
BACKGROUND \\
Fissure-in-ano is a common surgical problem. It causes a lot of pain. It causes loss of many functioning man-hours. Anal fissure is an \\
ulcer in the long axis of lower anal canal. The aim of this study is to find out the effectiveness of lateral internal sphincterotomy in \\
anal fissure. Perianal pain forms large volume of patients in any surgical OPD.
\end{tabular}

\section{MATERIALS AND METHODS}

A case series of 100 patients at the Surgery Department of a Medical College and Tertiary Health Care Centre over a period of 6 months that included cases of fissure-in-ano in the age group of $18 \mathrm{yrs}$. and above for surgical management.

\section{RESULTS}

The pain relief of the patients after this operation was fast and very satisfactory. On followup at 2 weeks post-operatively, pain and other symptoms were present in only 19 patients (19\%). On followup at 8 weeks post-operatively, all the 100 patients were symptom free (100\%) in this study. The complications that were observed during this study were soiling in 9 patients ( $9 \%)$ and incontinence to flatus in 3 patients (3\%). There was no recurrence of anal fissure observed in this study group.

\section{CONCLUSION}

From the above study, it is proved that lateral internal sphincterotomy is by far the best operation for fissure-in-ano.

\section{KEYWORDS}

Fissure-in-Ano, Lateral Sphincterotomy, Complications.

HOW TO CITE THIS ARTICLE: Subramaniam RK, Josephine J. A study of 100 cases of lateral internal sphincterotomy for fissure-inano. J. Evolution Med. Dent. Sci. 2017;6(91):6414-6416, DOI: 10.14260/jemds/2017/1395

BACKGROUND
Perianal pain forms large volume of patients in any surgical
management of anal fissure.

OPD. Fissure-in-ano is a common surgical problem. It causes a lot of pain. It causes loss of many functioning man-hours. Anal fissure is an ulcer in the long axis of lower anal canal.

Young individuals of both sexes are equally affected. Patient present with severe anal pain during defecation and/or rectal bleeding. Chronicity of a fissure relates to duration of greater than 6 weeks.

Most fissures occur in the posterior midline. This may be anatomically related, as there is a lack of tissue support posteriorly within the anal canal. Fissures associated with pregnancy are commonly located anteriorly. Other causes of fissures include Crohn's disease, syphilis, human immunodeficiency virus (HIV) or tuberculosis. These are secondary fissures.

The exact aetiology of primary anal fissure is unknown. High resting anal pressure and reduced vascular perfusion at the base caused by increased internal sphincter tone appears to be the underlying pathological factor. We manage large number of patients of anal fissure.

'Financial or Other Competing Interest': None.

Submission 08-10-2017, Peer Review 02-11-2017,

Acceptance 09-11-2017, Published 27-11-2017.

Corresponding Author:

Dr. Ravichandran Kailasam Subramaniam,

Associate Professor,

Department of General Surgery,

MAPIMS, Melmaruvathur,

Tamilnadu-603319.

E-mail: drksravichandranms@yahoo.com

DOI: $10.14260 /$ jemds $/ 2017 / 1395$

\section{Objective}

To find out the effectiveness of lateral internal sphincterotomy in anal fissure.

\section{MATERIALS AND METHODS}

\section{Inclusion Criteria}

Study was carried out on patients aged 18 yrs. and above, who were diagnosed clinically as anal fissure and attended the surgery outpatient clinic.

\section{Exclusion Criteria}

- Age less than 18 yrs.

- Important secondary changes in the anal fissure such as cicatricial deformation, large sentinel pile and subfissural infiltration.

- Any previous anal surgery.

- Patient with systemic diseases (Diabetes Mellitus, chronic liver disease and collagen vascular diseases).

- $\quad$ Patients under treatment with diltiazem or nitroglycerin for other diseases such as ischaemic heart diseases.

- Pregnant women were also excluded from the study.

- Study of anal fissure associated with other local diseases such as internal piles, fistula with diseases like inflammatory bowel disease and rectal cancer.

\section{Methodology}

The study was carried out as a Case Series of 100 patients at surgery department of a medical college and tertiary health care centre over a period of 6 months that included cases of anal fissure in the age group of 18 yrs. and above for 
conservative and surgical management. In this study, the case definition of anal fissure was-

- $\quad$ Evidence of posterior circumscribed ulcer with a large sentinel tag of skin.

- Induration at the edges.

- Exposure of horizontal fibres of the internal anal sphincter (IAS).

- Symptoms such as post defecatory or nocturnal pain, bleeding or both and pruritus ani lasting for more than 2 months and constipation.

- $\quad$ Each patient in the study was informed in detail about the aim of the study and the type of the procedure.

- A fully informed written consent was obtained from him/ her prior to the study.

- Appropriate ethical committee approval was taken.

- First a conservative trial was given to all the patients of anal fissure with either diltiazem or nitroglycerin ointment. Patients with persistent fissure at the end of the treatment with diltiazem or nitroglycerin were subjected to lateral internal sphincterotomy.

- All patients subjected to lateral internal sphincterotomy were treated by the same surgeons using uniform method of lateral sphincterotomy in the lithotomy position (surgical procedure is mentioned later).

- $\quad$ All patients received stool softeners, daily sitz bath and fibre supplement diet.

- $\quad$ All the patients were followed up at 2 weeks interval for 8 weeks. In each followup visit, the patients were evaluated for the criteria mentioned later.

- All the patients were informed to report SOS in case of any side effects or adverse effects.

- All patients were followed up for three months for evidence of recurrence of the fissure and the presence of possible side effects.

- The complications of surgery in relation to incontinence and recurrence were observed only within the timeframe of this study. The other postoperative complications, e.g. soilage, pain and bleeding were studied.

- In our setup, anal manometry was not possible.

- All patients who underwent surgery received spinal or general anaesthesia.

Operative procedure (Lateral Internal Anal Sphincterotomy). This procedure was carried out under spinal anaesthesia or general anaesthesia in all the patients. Once in lithotomy position, $5 \mathrm{~mL}$ of $2 \%$ lignocaine + adrenaline was injected at the proposed site of incision at either 3 or 9'o clock position in the intersphincteric plane. This facilitated bloodless dissection. A transverse incision was made at 3 or 9'o clock position and blunt dissection was carried out in the plane between internal and external sphincters. The internal sphincter was dissected away from anal mucosa. Once free in both planes, the sphincter was grasped between two haemostats and was brought on to the surface of wound. The haemostats were kept for 30 seconds and lower half of sphincter (approximately $1 \mathrm{~cm}$ ) was divided with the help of scissors. The wound was left open and a small wick was placed to control oozing. The dressing was removed on first postoperative day after sitz bath. Patients were discharged on second postoperative day with advice to have sitz bath for next two weeks.

\section{RESULTS}

- Patients between the age of 31 to 40 yrs. (47.5\%) were affected commonly by anal fissure. The overall incidence of posterior anal fissure in all age groups was as follows: 60 male $(60 \%)$ and 40 female $(40 \%)$ patients.

- Pain was the commonest symptom observed (100\%) in all the patients. Bleeding was associated in $80 \%$ of patients. $70 \%$ of patients complained of constipation and $50 \%$ complained of pruritus ani.

- Local examination revealed posterior circumscribed ulcer and induration in all the patients $(100 \%)$ followed by sentinel (skin) tag in $60 \%$.

- The recovery of the patient after this marvellous operation was fast and the pain relief was dramatic. On followup at 2 weeks post-operatively, pain and other symptoms were present only in 28 patients $(28 \%)$. On followup at 8 weeks post-operatively, all 100 patients $(100 \%)$ were symptom free in this study.

- The fissure healing after lateral internal sphincterotomy was very fast with $85 \%$ fissure healing (85 patients) within 4 weeks postoperative.

- $97.5 \%$ fissure healing, 98 patients at 8 weeks postoperatively.

- The defects of continence were minimal after lateral internal sphincterotomy. Soiling of undergarments was seen in 10 patients $(10 \%)$ and incontinence to flatus was seen in 3 patients $(3 \%)$.

\section{DISCUSSION}

The anal fissure is an ulcer in the skin lined part of the anal canal. It occurs most frequently in young adults and affects both sexes equally. ${ }^{1}$ The great majority of fissures occur in the posterior midline, although anterior midline fissures are seen in $25 \%$ in affected women and $8 \%$ in affected men. ${ }^{2}$ About $3 \%$ of patients have both anterior and posterior fissures.

Anal fissure is probably secondary to overstretching of the anoderm during the passage of a large or hard stool.3,4 WE Miles had postulated the passage of a scybalum over that part of the anal canal, which was relatively immobile, i.e. the part situated over the so-called pectin band, developed as a result of constipation just above Hilton's line?

In our study, we found that average age incidence was 39 yrs. and the patients in the age of $31-40$ yrs. were the commonest sufferers. Anal fissure produces pain out of proportion to its size and thus causes much discomfort.

Out of 100 patients studied, 60 were male $(60 \%)$ and 40 were female $(40 \%)$ patients. Posterior fissure was the inclusion criteria of this study. James G Petros et $\mathrm{al}^{5}$ have found that chronic fissures were equally common in males and females, and that in both sexes most fissures were located posteriorly.

Pain was the most common symptom (100\%), often associated with bleeding per rectally $(80 \%)$ followed by constipation (70\%) and pruritus ani $(50 \%)$. While studying the clinical presentations of anal fissures James G Petros et $\mathrm{al}^{5}$ have found that pain, bleeding and pruritus were the commonest symptoms. Patients who presented with bleeding were significantly younger than those without bleeding. In this study, bleeding was most commonly seen in the age group of 31 to 40 yrs. (48\%).

The operative management of anal fissure was aimed to cause permanent functional changes in the internal sphincter. 
It has been shown that the resting tone of internal anal sphincter is higher in patients of chronic anal fissure. The computerised profiles of anal canal with the aid of manometry $^{6}$ has shown that operative intervention significantly reduces the tone of internal anal sphincter, but still remains higher than normal making such persons prone to develop fissure. Xynos et $\mathrm{al}^{7}$ observed that increased anal sphincter activity was a major factor in anal fissure pathogenesis, and that successful internal sphincterotomy helps to heal fissure and improve the manometric performance of sphincter.

Sphincterotomy was initiated with the idea of decreasing the spasm of pectin band, which was shown to be nothing but internal sphincter. Notaras ${ }^{8}$ developed the technique of lateral subcutaneous sphincterotomy. It was simpler and quick procedure, which produced a small wound. Postoperative wound infection was negligible.

The reduction in the symptoms occurred immediately after lateral sphincterotomy. On followup at 2 weeks postoperatively the symptoms of pain, bleeding and pruritus ani were present in 28 patients (28\%). This number reduced significantly throughout the study period and on followup at 8 weeks post-operatively. All the 100 patients (100\%) were symptom free. Garcea et al reported persistence of symptoms after conservative sphincterotomy in $11.9 \%$ with only $9.2 \%$ needing topical analgesia.

In this study, complete healing of fissures occurred in $85 \%$ within 4 weeks post-operatively and by the end of 8 weeks fissures healed in $98 \%$ patients. The average time taken for fissure healing after lateral internal sphincterotomy was three and a half weeks in PR Hawley's series ${ }^{9}$ and 3 weeks in Notaras' series. ${ }^{8}$

In our study, the postoperative complications that occurred were soiling of undergarments in $10(10 \%)$ patients and incontinence to flatus in $3(3 \%)$ patients. Series of Hoffmann and Goligher reported incontinence to flatus in $6 \%$ patients and soiling of undergarments in $7 \%$ patients.

Collopy and Ryan found that on the basis of fewer recurrences and less incontinence, sphincterotomy appeared superior to manual stretch. ${ }^{10}$

Jensen suggested that lateral sphincterotomy was superior to manual stretch on the basis of fewer persistence/ recurrent fissures.11 The pain relief and minimal complications were the same as was the healing time. Hoffmann and Goligher ${ }^{12,13}$ compared posterior sphincterotomy, lateral sphincterotomy and sphincter stretch and favoured lateral sphincterotomy.

There was no recurrence of anal fissure observed in this study group within the timeframe of this study. According to reports after lateral internal sphincterotomy, the long-term results were excellent and the recurrence rate was low.7,9,14

\section{CONCLUSION}

From the above study, it has been proved that a simple 'Lateral internal sphincterotomy' can cure the extremely painful chronic anal fissure. It is evident from the above study that 'lateral internal sphincterotomy' is by far the best operation for an indolent anal fissure because-

- Pain relief is immediate.

- Fissure healing is very fast.

- Defects of anal continence after this procedure are negligible.

- Extremely low rate of recurrence.

\section{REFERENCES}

[1] Schouten WR, Briel JW, Auwerda JJ, et al. Ischemic nature of anal fissure. Br J Surg 1996;83(1):63-5.

[2] Lund JN, Scholefield JH. Aetiology and treatment of anal fissure. Br J Surg 1996;83(10):1335-44.

[3] Goligher JC. Chapters 1 and 5. Surgery of the Anus, Rectum and colon. $4^{\text {th }}$ edn. 1980.

[4] Hughes ESR. Anal fissure. BMJ 1970;3:673.

[5] James GP, Rimm EB, Renne JR. Clinical presentation of chronic anal fissure. Dept of surgery, Harward school of public health, Boston. American Surgeon 1993;59:666-7.

[6] Keck JO, Staniunas RJ, Coller JA, et al. Computer generated profiles of anal canal in patients with anal fissure. Dept of colon and rectal surgery Lahey clinic, Massachusetts. Dis Colon \& Rectum 1995;38(1):72-9.

[7] Xynos E, Tzortzinis A, Chrysos E, et al. Anal manometry in patients with fissure-in-ano before and after internal sphincterotomy. Int J Colorectal Disease 1993;8(3):125-8.

[8] Notaras MJ. The treatment of anal fissure by lateral subcutaneous internal sphincterotomy a technique and results. Br J Surg 1971;58(2):96-100.

[9] Hawley PR. Treatment of chronic anal fissure-in-ano. A trial of methods. Br J Surg 1969;56(12):915-8.

[10] Collopy B, Ryan P. Comparison of lateral subcutaneous sphincterotomy with anal dilatation in the treatment of fissure in ano. The Med J of Australia 1979;2(9): 461-2, 487.

[11] Jensen SL, Lund E, Nielsen OV, et al. Lateral subcutaneous sphincterotomy versus anal dilatation in the treatment of fissure in ano in outpatients: a prospective randomized study. BMJ (Clin Res Ed) 1984;289(6444):528-30.

[12] Hoffmann DC, Goligher JC. Lateral subcutaneous internal sphincterotomy in treatment of anal fissure. Br Med J 1970;3(5724):673-5.

[13] Goligher JC. An evaluation of internal sphincterotomy and simple sphincter stretching in the treatment of anal fissure. Surg clin North Am 1965;42:1299.

[14] Abcarian HMD. Lateral internal sphincterotomy. A new technique for treatment of chronic fissure in ano. SCNA 1975:55-143. 